\title{
Subject Status Reason Not Done
}

National Cancer Institute

\section{Source}

National Cancer Institute. Subject Status Reason Not Done. NCI Thesaurus. Code

C117666.

The rationale why a subject status assessment was not performed. 